\title{
Alveolar Epithelial Cell Differentiation and Surfactant Protein Expression After Mild Preterm Birth in Sheep
}

\author{
FOULA SOZO, MEGAN J. WALLACE, MARY R. HANNA, SHARON J. FLECKNOE, MEGAN L. COCK, GERT S. MARITZ, \\ RICHARD HARDING, AND STUART B. HOOPER
}

\author{
Department of Physiology [F.S., M.J.W., M.R.H., S.J.F., M.J.C., R.H., S.B.H.], Monash University, Victoria 3800, Australia; \\ Department of Human Biosciences [G.S.M.], University of the Western Cape, 7535 Bellville, South Africa
}

\begin{abstract}
As the transition to extrauterine life at birth alters the proportions of type I and II alveolar epithelial cells (AECs), our aim was to determine the effect of mild preterm birth on AECs and surfactant protein (SP) gene expression. Preterm lambs were born at $\sim 133 \mathrm{~d}$ of gestational age (DGA); controls were born at term ( $\sim 147$ DGA). Lungs were collected from preterm lambs at termequivalent age (TEA; $\sim 2 \mathrm{wk}$ after preterm birth) and $6 \mathrm{wk}$ post-TEA. Control lung tissue was collected from fetuses (at 132 DGA), as well as from lambs at $\sim 6 \mathrm{~h}$ (normal term) and 2,6 , and $8 \mathrm{wk}$ of postnatal age (PNA). In controls, the proportion of type I AECs decreased from $65.1 \pm 3.9 \%$ at term to $50.9 \pm 3.3 \%$, while the proportion of type II AECs increased from $33.7 \pm 3.9 \%$ to $48.5 \pm 3.3 \%$ at $6 \mathrm{wk}$ PNA. At 2 wk after preterm birth, the proportions of type I and II AECs were similar in preterm lambs compared to 132-d fetal levels and term controls but differed from control values at 2 wk PNA; differences between control and preterm lambs persisted at 8 wk PNA. At $\sim 2$ wk after preterm birth, SP-A and SP-B, but not SP-C, mRNA levels were significantly reduced in preterm lambs compared with term controls, but these differences did not persist at 2 and 6 wk PNA. We conclude that mild preterm birth alters the normal postnatal changes in type I and II cell proportions but does not severely affect SP gene expression. (Pediatr Res 59: 151-156, 2006)
\end{abstract}

$\mathrm{P}$ reterm birth occurs in $\sim 11.6 \%$ of births and is the greatest cause of neonatal morbidity and mortality, much of which is due to pulmonary immaturity (1). Depending on gestational age at delivery, preterm birth can lead to respiratory distress and chronic lung disease and may have long-term sequelae (2). Due to confounding factors associated with respiratory support, the impact of preterm birth per se on lung development is largely unknown. A recent study in mildly preterm infants not exposed to ventilatory support suggested preterm birth per se affects the formation of alveoli and elastic tissue (3). Of particular interest is the effect of mild preterm birth on the alveolar epithelium as it is involved in alveolar development, gas exchange, and surfactant production.

During fetal life, the lungs are expanded with luminal liquid, which is important for lung development $(4,5)$. How-

Received January 13, 2005; accepted July 5, 2005.

Correspondence: Stuart Hooper, Ph.D., Department of Physiology, P.O. Box 13F, Monash University, VIC 3800, Australia; e-mail: stuart.hooper@med.monash.edu.au

R.H. and S.B.H. are joint senior authors.

This work was funded by the National Health and Medical Research Council of Australia.

DOI: 10.1203/01.pdr.0000190574.94285.a2 ever, with lung aeration at birth, lung recoil increases due to the formation of an air-liquid interface and hence the development of surface tension within alveoli (4); as a result, basal lung expansion decreases (4). During fetal life, the basal degree of lung expansion has a major impact on lung growth, lung structure, and alveolar epithelial cell (AEC) differentiation (5-8). As preterm birth causes a premature increase in lung recoil, this is likely to have a major impact on these developmental processes that usually occur late in gestation. In the fetus, increased lung expansion promotes differentiation into the type I AEC phenotype, whereas reduced lung expansion promotes the type II AEC phenotype $(6,8,9)$. Similar effects of mechanical strain on AEC phenotypes have been reported in vitro $(10,11)$. Consistent with these findings, the reduction in lung expansion at birth is associated with an increase in the proportion of type II AECs and a reduction in the proportion of type I AECs (12). Thus, it is likely that preterm birth adversely affects AEC development due to a premature reduction in lung expansion.

Although it seems likely that preterm birth per se could affect AEC differentiation, this has not been studied directly and it is not known how long any effects may persist into postnatal life. Thus, our objective was to determine a) the effects of mild preterm birth, in the absence of sustained ventilatory support, on the differentiation of AECs and surfactant protein mRNA expression and b) the persistence of these changes into early postnatal life. We hypothesized that preterm birth would cause a premature increase in the proportion of type II AECs and a premature decrease in the proportion of type I AECs, with parallel changes in SP gene expression, and that these changes would persist into postnatal life.

\section{METHODS}

Experimental procedure. All procedures were approved by the Monash University Animal Ethics Committee. Pregnant ewes were divided into either a control group $(n=11)$ or a preterm group $(n=12)$ and all received betamethasone ( $3 \mathrm{mg}$, i.m., Celestone Chronodose, Schering-Plough, Australia) at $131 \mathrm{DGA}$ to ensure survival of preterm lambs. Control ewes delivered

Abbreviations: AECs, alveolar epithelial cells; DGA, days of gestational age; PNA, postnatal age; SP, surfactant protein; TEA, term-equivalent age 
lambs at term $(\sim 147$ DGA). Ewes in the preterm group were administered Epostane (50 mg, i.v., Sanofi-Synthlabo, PA) at 131 DGA to induce delivery at 133 DGA.

One group of controls and one group of preterm lambs were humanely killed (Na-pentobarbitone, $1624 \mathrm{mg}$, i.v.) at TEA, which was $\sim 6 \mathrm{~h}$ after birth for control lambs $(n=6)$ and $\sim 2$ wk after preterm birth for preterm lambs $(n$ $=6$ ). The other two groups of lambs were killed at $6 \mathrm{wk}$ post-TEA; this was at $6 \mathrm{wk}$ after term birth for controls $(n=5)$ and $8 \mathrm{wk}$ after birth for preterm lambs $(n=6)$. At necropsy, the lungs were weighed, the left bronchus ligated, the left lung removed, and portions were frozen in liquid $\mathrm{N}_{2}$ and stored at $-70^{\circ} \mathrm{C}$. The right lung was fixed for histologic analysis (13).

Tissue was also obtained from fetuses at 132 and 142 DGA $(n=5$ per group) and from postnatal lambs at 2 and $8 \mathrm{wk}$ after term birth $(n=5$ per group). These tissues had previously been collected by us $(12,14)$ and provided additional control material for comparison with fetal levels just before the two delivery ages and to compare our preterm lambs with lambs at equivalent postnatal ages, i.e. at 2 and 8 wk after birth.

Tissue processing. Following fixation, the right lung was cut into $5 \mathrm{~mm}$ slices (in cross section), and every second slice was further divided into three sections. At least six sections were chosen at random (two per lobe) and cut into cubes $\left(\sim 2 \mathrm{~mm}^{3}\right)$, avoiding major airways and blood vessels. Tissue cubes were postfixed in $4 \%$ glutaraldehyde at $4^{\circ} \mathrm{C}$ overnight, washed in $0.1 \mathrm{~mol} / \mathrm{L}$ cacodylate buffer, incubated in $2 \% \mathrm{OsO}_{4}$ (in $0.1 \mathrm{~mol} / \mathrm{L}$ cacodylate buffer) for $2 \mathrm{~h}$, dehydrated, and then embedded in epoxy resin (Procure 812, ProSciTech, Australia). Coded ultrathin sections $(70-90 \mathrm{~nm}$ ) were cut using a diamond knife, mounted on 200-mesh copper grids, and stained with saturated uranyl acetate and lead citrate.

Cell counting and identification. We chose to identify AECs using morphologic criteria identified by transmission electron microscopy (TEM) $(8,9,12)$ rather than by light microscopy using stains for specific cell markers; it is currently unclear which markers should be used to categorically identify differentiating AECs in sheep. Although SPs are commonly used to identify type II AECs, SPs are expressed in the fetal sheep lung before morphologically distinct type II AECs appear (12). Furthermore, $\mathrm{T} 1_{\alpha}$, a type I AEC marker in rats and mice, has not been identified in sheep and AQP5 mRNA, another marker for type I AECs, is reduced when type I AEC proportions are increased in response to an increase in fetal lung expansion $(9,15)$.

Using a transmission electron microscope (JEOL 100s) at $60 \mathrm{kV}$, at least 100 AECs with a nuclear profile were categorized and counted as undifferentiated, type I, type II, or intermediate AECs, based on morphologic appearance (9). The identification of AECs required visualization of the basement membrane, with all AECs lying on its luminal surface. The volume densities of mitochondria, lamellar bodies, cytoplasm, and nuclei of the type II cells were determined by point counting $(16,17)$ using tissue from at least five sheep per group. Preparation of transmission electron micrographs of type II AECs and determination of the type II volume densities were performed blind, and at least six cells per lung were used (minimum of 30 cells/group).

$\boldsymbol{S P}$ expression. SP-A, -B, and -C mRNA levels in lung tissue were quantified by Northern blot analysis, as described previously (18). Total RNA was extracted and $20 \mu \mathrm{g}$ of RNA was denatured, loaded into separate wells and electrophoresed on a $1 \%$ agarose gel, containing $2.2 \mathrm{~mol} / \mathrm{L}$ formaldehyde. RNA was transferred to a nylon membrane (Duralon, Bio-Rad, Australia) and cross-linked by UV light (Hoeffer UVC500, Hoeffer). The membranes were hybridized with ovine-specific ${ }^{32} \mathrm{P}$-labeled cDNA probes (18); they were washed, sealed in airtight bags, and exposed to a storage phosphor screen at room temperature for 2-4 d. A digital image was obtained using a phosphorimager (Storm 860, Molecular Dynamics, Sunnyvale, CA) before the membranes were stripped and rehybridized with a ${ }^{32} \mathrm{P}$-labeled cDNA probe for $18 \mathrm{~S}$ rRNA. The relative amounts of each SP mRNA were analyzed by measuring the density of each band (ImageQuaNT software, Molecular Dynamics) and are expressed as a proportion of the density of the 18S rRNA band for that lane and as a percentage of control values.

Statistical analysis. Results are presented as mean \pm SEM. Differences in proportions of AECs and SP expression between treatment and age groups were determined using one-way analysis of variance (ANOVA). Following a significant one-way ANOVA, a least significant difference (LSD) post hoc test was used. A Student's unpaired $t$ test was used to test differences in SP expression between the preterm lambs at TEA and control lambs at $2 \mathrm{wk}$ PNA. A $p$ value of $<0.05$ was taken to be statistically significant.

\section{RESULTS}

Outcome of preterm birth. Preterm lambs were mildly hypoxemic as determined by transcutaneous oxygen saturation $(<70 \%)$ immediately after birth. Although some lambs were briefly provided with nasal oxygen, none required intubation, resuscitation, or ventilatory support and all reached $\mathrm{SaO}_{2}$ values of $>95 \%$ within $2-12 \mathrm{~h}$ after birth. Preterm lambs were kept warm and fed expressed ewe's milk approximately every 3-4 $\mathrm{h}$ until strong enough to feed from their mothers (1-4 d after birth). Preterm lambs had lower birth weights $(3.6 \pm 0.1 \mathrm{~kg})$ than controls $(4.5 \pm 0.3 \mathrm{~kg}, p<0.05)$ due to their younger gestational age at birth. By 2 wk after birth (i.e. TEA), however, preterm lambs weighed more (5.9 $\pm 0.4 \mathrm{~kg})$ than control lambs at birth $(4.5 \pm 0.3 \mathrm{~kg}, p<0.05)$. At 6 wk post-TEA, weights of preterm lambs $(15.1 \pm 0.3 \mathrm{~kg})$ and controls were not different $(14.8 \pm 0.3 \mathrm{~kg})$. Cohorts of control and preterm lambs consisted of similar numbers of males and females; thus, differences in results are unlikely due to gender differences.

\section{Proportions of alveolar epithelial cells}

Type I AECs (Fig. 1A). In control lambs born at term (i.e. $\sim 6 \mathrm{~h}$ PNA), the proportion of type I AECs $(65.1 \pm 3.9 \%)$ was similar to that in control fetuses at 132 DGA $(71.6 \pm 2.6 \%)$ and at 142 DGA $(68.9 \pm 3.6 \%)$. However, by $2 \mathrm{wk}$ after term birth, the proportion of type I AECs had decreased to $44.8 \pm$ $1.8 \%(p<0.001)$ and remained at similar values at $6 \mathrm{wk}(50.9$ $\pm 3.3 \%)$ and $8 \mathrm{wk}(45.5 \pm 2.9 \%)$. At $\sim 2 \mathrm{wk}$ after preterm birth (i.e. TEA), the proportion of type I AECs was $63.8 \pm$ $3.7 \%$ in preterm lambs, which was not significantly different
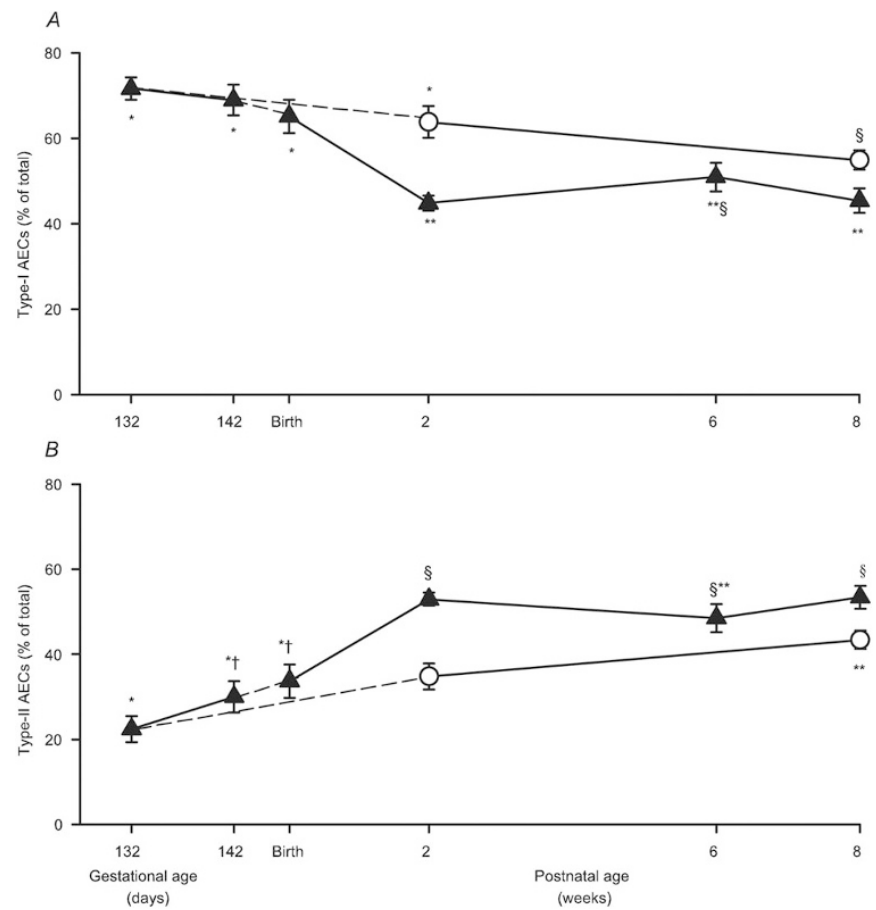

Figure 1. Type I and II AEC proportions following preterm birth. Proportions of type I $(A)$ and II $(B)$ AECs were measured in control fetuses (filled triangles $)$ at 132 and 142 DGA and in control lambs born at term $(\sim 147$ DGA), at $\sim 6 \mathrm{~h}, 2 \mathrm{wk}(n=4$ per group), $6 \mathrm{wk}(n=5)$, and 8 wk after birth $(n=4)$. In preterm lambs (born at $\sim 133$ DGA; open circles) the proportions of type I $(A)$ and II $(B)$ AECs were measured at $\sim 2$ wk after preterm birth (at TEA, $n=6)$ and at 8 wk after birth ( 6 wk post-term equivalent age, $n=5$ ). For each cell type, values that do not share a common symbol are significantly different from each other $(p<0.05)$. 
to values in controls at $132 \mathrm{DGA}(p=0.09)$ and $142 \mathrm{DGA}$ and in controls at $\sim 6 \mathrm{~h}$ after birth. In preterm lambs, the proportion of type I AECs $(54.9 \pm 2.3 \%)$ at $8 \mathrm{wk}$ (i.e. $6 \mathrm{wk}$ post-TEA) was lower than at TEA $(63.8 \pm 3.7 \%, p<0.05)$ but had not reached the value in controls aged 8 wk $(45.5 \pm$ $2.9 \%, p<0.05)$.

Type II AECs (Fig. IB). The proportion of type II AECs in control lambs at $\sim 6 \mathrm{~h}$ after birth $(33.7 \pm 3.9 \%)$ was similar to that in fetuses at $132 \mathrm{DGA}(22.4 \pm 3.1 \%)$ and just before birth (at $142 \mathrm{DGA} ; 30.0 \pm 3.7 \%$ ). However, in controls, the proportion of type II AECs was significantly greater at $2 \mathrm{wk}$ $(52.9 \pm 1.5 \%, p<0.001), 6$ wk $(48.5 \pm 3.3 \%, p<0.005)$, and $8 \mathrm{wk}(53.4 \pm 2.7 \%, p<0.001)$ after birth compared with $6 \mathrm{~h}$ after birth. In preterm lambs, the proportion of type II AECs at 2 wk after preterm birth (i.e. at TEA; $34.8 \pm 3.1 \%$ ) was not significantly different from values in fetuses just before term birth $(\sim 142 \mathrm{DGA} ; 30.0 \pm 3.7 \%)$ and in control lambs at $\sim 6 \mathrm{~h}$ after birth $(33.7 \pm 3.9 \%)$. Although the proportion of type II AECs in preterm lambs increased significantly at 8 wk PNA $(43.4 \pm 2.1 \%)$ compared with 2 wk PNA (34.8 $\pm 3.1 \%, p<0.05)$, type II AEC proportions were still significantly $(p<0.05)$ lower than in control lambs at 8 wk PNA $(53.4 \pm 2.7 \%)$.

Undifferentiated and intermediate AECs. Few undifferentiated AECs $(<1 \%)$ were observed in any of the groups. Proportions of intermediate AECs were similar in control (1.2 $\pm 0.2 \%)$ and preterm $(1.3 \pm 0.9 \%)$ lambs at $2 \mathrm{wk}$ after birth; these values did not alter significantly with age.

Type II cell morphometry. Electron micrographs of typical type II AECs at birth (TEA) and 6 wk after birth (6 wk post-TEA) in control lambs and at 2 wk (TEA) and $8 \mathrm{wk}$ (6 wk post-TEA) after preterm birth are shown in Figure 2. Volume densities of nuclei and cytoplasm in type II cells were not different between groups at both TEA and $6 \mathrm{wk}$ post-TEA (Table 1). Volume density of lamellar bodies in preterm lambs tended to be greater than in controls at both TEA (preterm:

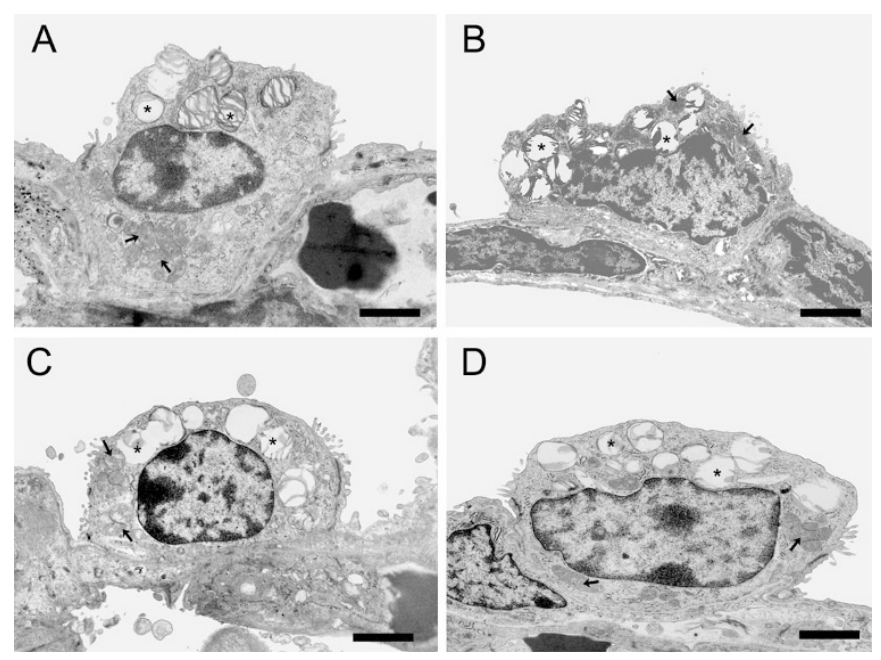

Figure 2. Electron micrographs of typical type II AECs. Type II AECs from control lambs at term birth $(A)$, preterm lambs at TEA $(\sim 2 \mathrm{wk}$ after preterm birth) $(B)$, controls aged $6 \mathrm{wk}(C)$, and preterm lambs aged $8 \mathrm{wk}(6 \mathrm{wk}$ post-TEA) (D). Arrows show mitochondria; asterisks show lamellar bodies. Bar $=2 \mu \mathrm{m}$.
$23.7 \pm 1.4 \%$ versus control: $20.9 \pm 1.7 \% ; p=0.2)$ and $6 \mathrm{wk}$ post-TEA (preterm: $23.3 \pm 1.4 \%$ versus control: $19.3 \pm$ $1.4 \% ; p=0.1)$; however, this was not significant. At TEA, the volume density of mitochondria in type II cells of preterm lambs was significantly lower $(3.3 \pm 0.3 \%)$ than in controls $(5.9 \pm 0.9 \%, p=0.001)$, but this difference resolved by $6 \mathrm{wk}$ post-TEA.

SP $\boldsymbol{m} \boldsymbol{R} N \boldsymbol{A}$ levels. At $2 \mathrm{wk}$ after preterm birth (TEA), SP-A mRNA levels $(65.0 \pm 12.3 \%)$ were significantly lower than in those of controls at TEA $(100.0 \pm 5.4 \%, p<0.05$; Fig. $3 A)$. Similarly, SP-B expression in preterm lambs was $54.0 \pm 7.1 \%$ of values in controls at TEA $(100.0 \pm 6.6 \%, p<0.001$; Fig. 3B). SP-C mRNA levels were not different in preterm lambs $(85.5 \pm 14.6 \%)$ compared with TEA controls (100.0 \pm 12.0\%; Fig. 3C). There were no differences in SP-A, SP-B, and SP-C mRNA levels between preterm lambs at $2 \mathrm{wk}$ after preterm birth (TEA; SP-A: $81.0 \pm 17.0$; SP-B: $88.6 \pm 9.8 \%$; SP-C: $116.7 \pm 22.6 \%$ ) and controls at $2 \mathrm{wk}$ after normal term birth ( 2 wk post-TEA; SP-A: $100.0 \pm 12.0$; SP-B: $100.0 \pm$ 8.1\%; SP-C: $100.0 \pm 6.4 \%$ ). Furthermore, there were no significant differences in SP-A, -B, or -C mRNA levels between the control lambs and preterm lambs at 6 wk post-TEA (Fig. 3). SP-A and SP-C mRNA levels were not different at TEA ( $2 \mathrm{wk}$ after preterm birth) and $6 \mathrm{wk}$ post-TEA ( $8 \mathrm{wk}$ after preterm birth) in both control and preterm lambs; SP-B expression decreased with age in the control lambs only.

\section{DISCUSSION}

It is well established that the fetal lungs are maintained in a distended state by luminal liquid. However, at birth, the increase in lung recoil due to aeration causes a $\sim 50 \%$ reduction in the level of basal lung expansion (4). Due to the close relationship between the degree of lung expansion and the differentiated state of AECs (8), we hypothesized that preterm birth would prematurely alter the proportions of type I and II AECs as observed after normal term birth (12). However, at $2 \mathrm{wk}$ after preterm birth, preterm lambs had type I and II AEC proportions that were similar to values in late gestation fetuses and newborn control lambs. Despite having similar proportions of type II AECs, SP-A and SP-B mRNA levels were significantly reduced in preterm lambs, suggesting that the expression level per type II cell may have been reduced. Furthermore, at $8 \mathrm{wk}$ after preterm birth, the proportions of type I and II AECs had not reached those of control lambs at 8 wk of age, indicating that the normal postnatal changes in AEC differentiation are delayed or permanently altered following mild preterm birth.

We, and others, have shown that throughout late gestation in sheep, the proportions of type I (60-65\%) and type II AECs (30-35\%) remain relatively constant, with type I AECs being the more common cell type (12). However, by 2 wk after term birth, these proportions are significantly altered and type II AECs predominate (12). In normal animals, these proportions do not change further during postnatal development and are similar at $2 \mathrm{y}$ of age (12). The mechanisms responsible for these birth-related changes in AEC proportions are unknown. However, it has been suggested that an increase in lung recoil 
Table 1. Density of organelles in type II cells

\begin{tabular}{|c|c|c|c|c|}
\hline Organelle & \multicolumn{2}{|c|}{ TEA } & \multicolumn{2}{|c|}{6 weeks post-TEA } \\
\hline Lamellar bodies & $20.9 \pm 1.7$ & $23.7 \pm 1.4$ & $19.3 \pm 1.4$ & $23.3 \pm 1.4$ \\
\hline Nucleus & $33.2 \pm 2.7$ & $34.5 \pm 2.6$ & $34.3 \pm 2.9$ & $27.9 \pm 2.8$ \\
\hline Cytoplasm & $40.8 \pm 2.9$ & $38.5 \pm 2.4$ & $41.4 \pm 2.8$ & $44.7 \pm 3.4$ \\
\hline
\end{tabular}

The percentage (\%) of area of organelles within type II cells in preterm and control lambs. Mean values are presented at both TEA and 6 wk post-TEA.

* Significant difference $(p<0.001)$ between control lambs and preterm lambs at TEA.

and a reduction in lung expansion associated with lung aeration at birth may induce type I to type II AEC transdifferentiation (12). Previous studies have indicated that a sustained increase in the degree of lung expansion promotes the differentiation of type II AECs into type I AECs $(6,8,9,19)$ via an intermediate cell type $(8,9)$. In contrast, a sustained reduction in lung expansion is thought to promote type I to type II AEC transdifferentiation (8). The time course for the changes in AEC proportions after birth is also unknown, although our results indicate that they have not begun within $6 \mathrm{~h}$ of birth as newborn control lambs had type I and II AEC proportions that were similar to those of fetal values. This is supported by the finding that the proportion of intermediate AECs was not elevated at this time; an elevated proportion of intermediate AECs has previously been used to indicate an increased rate of AEC transdifferentiation $(8,9)$.

Although we found that proportions of type I $(50.9 \pm 3.3 \%)$ and type II $(48.5 \pm 3.3 \%)$ AECs were similar in control lambs at $6 \mathrm{wk}$ after birth, we have previously shown that type II AECs predominate (50-53\% versus $45-48 \%$ ) after birth at 2 and $8 \mathrm{wk}$ of age as well as at $2 \mathrm{y}$. These findings are consistent with those of previous studies indicating that type I and II AECs are present in approximately equal numbers after birth $(12,20)$. However, in preterm lambs the proportions of AECs still resembled the fetal state at both 2 and 8 wk after birth, respectively, with a higher proportion of type I cells (63.8 \pm $3.7 \%$ and $54.9 \pm 2.3 \%)$ than type II cells $(34.8 \pm 3.1 \%$ and 43.4 $\pm 2.1 \%)$. This demonstrates that mild preterm birth per se either permanently alters or substantially delays the increase in type II and decrease in type I AEC proportions that characterize the air-filled lungs after birth. Possible explanations include differences in end-expiratory lung volumes (FRC) arising from gas trapping or an increase in airway resistance in preterm lambs. This suggestion is consistent with the findings of a parallel study that we conducted showing that preterm birth leads to an increase in airway resistance (13). The impact of reduced type II cell proportions is unknown, although it seems likely that either total lung surfactant production is reduced or that surfactant production per type II cell is increased to maintain adequate surfactant levels; this may or may not be sustainable in the long term. This latter possibility is supported by the observation that despite the lower type II AEC proportions in preterm lambs, the lamellar body density per type II cell tended to be greater. The type II cells also had a lower mitochondrial density, which is a characteristic of type II cells in the immature lung $(17,21)$.
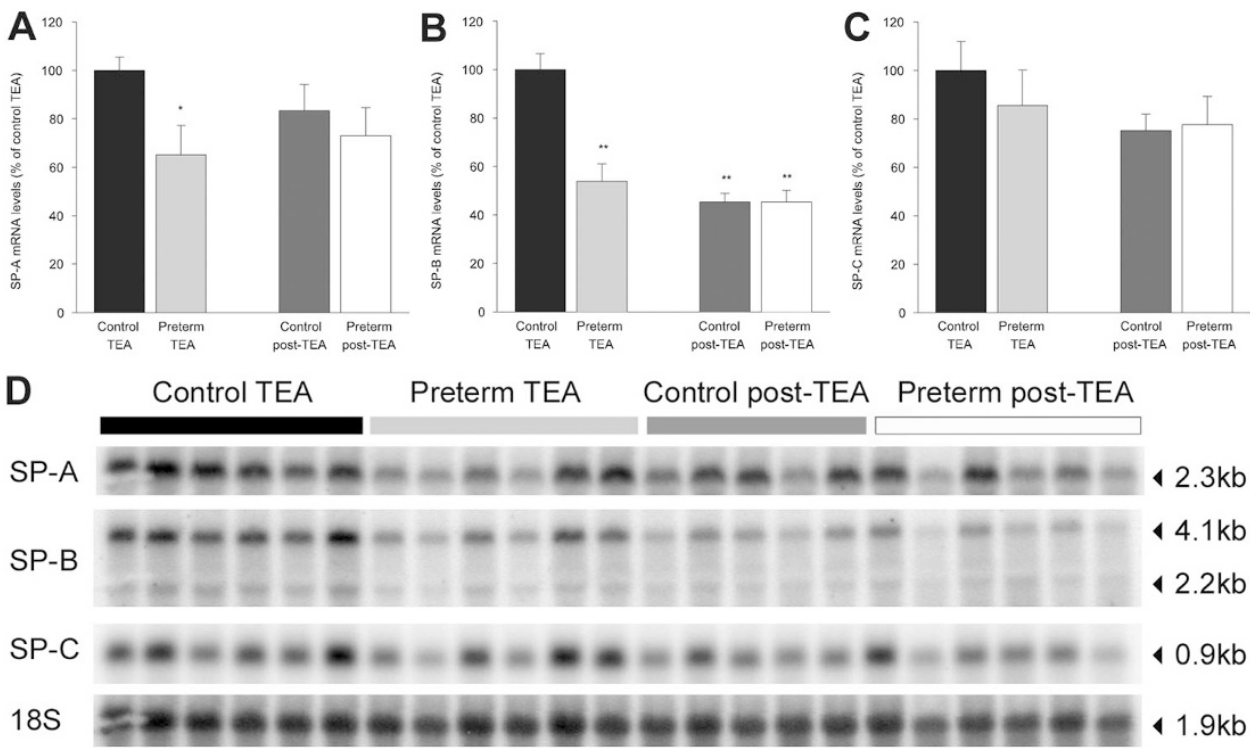

Figure 3. SP expression following preterm birth. The expression of SP-A $(A)$, SP-B $(B)$, and SP-C $(C)$ in control and preterm lambs at TEA $(\sim 6 \mathrm{~h}$ in controls and $\sim 2 \mathrm{wk}$ PNA in preterm lambs, $n=6$ per group) and at $6 \mathrm{wk}$ post-TEA $(\sim 8 \mathrm{wk}$ postnatal age in preterm lambs, $n=5$ controls and $n=6$ preterm lambs $)$. $* p<0.05$ and $* * p<0.001$ compared with control lambs at TEA. Northern blot of total RNA $(20 \mu \mathrm{g})$ from the lungs of control and preterm lambs at both TEA and 6 wk post-TEA is shown $(D)$. Each lane represents RNA from a different animal and each panel shows the same Northern blot hybridized with a SP-A, SP-B, SP-C, or $18 \mathrm{~S}$ rRNA ${ }^{32} \mathrm{P}$-labeled cDNA probe. 
In preterm lambs at TEA, the mRNA levels for SP-A and SP-B were lower than in control lambs of the same postconceptional age. These findings are consistent with other studies in which newborn preterm lambs at 125 DGA had SP mRNA levels that were only $15-40 \%$ of those in lambs born at term (22). We expected that changes in the expression of the SPs would correlate with changes in the proportion of AEC types, as we have observed previously $(8,9,12)$. However, the reductions in SP expression occurred despite similar proportions of type II AECs in preterm lambs at TEA (i.e. 2 wk after preterm birth) and newborn controls. This suggests that SP-A and SP-B expression per type II AEC is reduced in preterm lambs compared with controls at TEA. Although the mechanisms involved are unknown, reduced ATP production associated with lower mitochondrial densities may be involved. Whatever the mechanism, our data indicate that each of the SPs are differentially regulated after birth and can be regulated independently of AEC differentiation. This finding is consistent with previous studies demonstrating that each of the SPs can have a different pattern of expression following birth $(12,22-$ 24). Numerous transcription factors have been implicated in regulating SP expression $(25,26)$, and, therefore, it is possible that the differential SP gene expression is related to differences in their function $(27,28)$.

$\mathrm{SP}$ expression in preterm lambs at $2 \mathrm{wk}$ after preterm birth (TEA) is not different to that of controls at the same postnatal age (i.e. $2 \mathrm{wk}$ after birth). Labor in sheep is associated with a large increase in circulating fetal cortisol levels that is involved in the initiation of parturition in this species $(29,30)$. Thus, since the control lambs were killed at $6 \mathrm{~h}$ after birth, SP expression in the lungs may have still been under the influence of these highly circulating cortisol levels. As both cortisol and synthetic corticosteroids can stimulate SP expression in vivo, SP expression would be expected to be elevated in response to the preparturient surge in fetal cortisol $(31,32)$. Although SP expression is only marginally reduced in glucocorticoid receptor-deficient mice (33), the proportion of type II AECs is elevated compared with wild-type controls, indicating that SP expression per type II AEC is reduced (17). Our finding that SP expression is elevated in control lambs shortly after delivery, despite a lower proportion of type II AECs, compared with 2-wk-old controls, is therefore consistent with findings of previous studies and may be related to elevated circulating cortisol levels.

Although we gave betamethasone to the ewes of both control and preterm lambs, these injections were administered at 131 DGA, more than 2 wk before tissue collection. The administration of betamethasone ensured the viability of the preterm lambs without significant postnatal intervention. These injections were unlikely to have affected SP expression at the time of measurement as the effects of antenatal steroids are not sustained for longer than $7 \mathrm{~d}$ (22). Furthermore, both control and preterm lambs were given the same small dose at the same gestational age.

It has recently been shown that SP in tracheal aspirates from newborn preterm infants differs from samples taken from preterm infants more than 1 wk old (34). Furthermore, studies in preterm baboons have shown that SP expression levels increase within $24 \mathrm{~h}$ after birth, but by 6-10 d PNA, SP mRNA levels are reduced to values lower than those of term controls (35). Thus, it is possible that in our model, SP expression also increases immediately after preterm birth, perhaps due to phasic lung expansion during air breathing and that after this initial increase, expression levels decrease and remain at these values into postnatal life. Since we did not collect lung tissue from preterm lambs shortly after birth, these changes may have been missed in our study. However, by $8 \mathrm{wk}$ after preterm birth ( $6 \mathrm{wk}$ post-TEA), there is no apparent effect of preterm birth on SP expression despite the finding that the expected increase in type II AECs is significantly delayed or permanently altered in preterm lambs. This indicates that the type II cells may express SP mRNA at higher rates to compensate for the lower relative proportions of this cell type in preterm animals.

The detrimental effects of preterm birth on lung development and function observed in previous follow-up studies (2) could be partially due to the use of respiratory interventions required for neonatal survival. To avoid the need for the potentially confounding effects of respiratory intervention, we delivered lambs only mildly prematurely; hence, it is possible that they were not sufficiently premature to show these major detrimental effects on lung development. Indeed, the preterm lambs used in this study were born during the alveolar stage of development, which equates to $\sim 32$ wk gestational age in humans. If preterm birth had been induced earlier, the birthrelated reduction in lung expansion (compared with normal term birth) may have been greater, and, therefore, a greater effect may have been seen.

We conclude that mild preterm birth causes a delay in, or permanent alteration to, the changes in AEC proportions that normally occur after birth but does not appear to have any significant detrimental effects on SP expression in early postnatal life. Further studies that examine the long-term effects of preterm birth are needed to determine whether the effects of preterm birth per se on alveolar epithelial cells persist beyond the early postnatal period.

Acknowledgments. The authors gratefully acknowledge the expert technical assistance provided by Alison Thiel and Valerie Zahra.

\section{REFERENCES}

1. MacDorman MF, Minino AM, Strobino DM, Guyer B 2002 Annual summary of vital statistics-2001. Pediatrics 110:1037-1052

2. Doyle LW, Cheung MM, Ford GW, Olinsky A, Davis NM, Callanan C 2001 Birth weight $<1501 \mathrm{~g}$ and respiratory health at age 14. Arch Dis Child 84:40-44

3. Hjalmarson O, Sandberg K 2002 Abnormal lung function in healthy preterm infants. Am J Respir Crit Care Med 165:83-87

4. Harding R, Hooper SB 1996 Regulation of lung expansion and lung growth before birth. J Appl Physiol 81:209-224

5. Moessinger AC, Harding R, Adamson TM, Singh M, Kiu GT 1990 Role of lung fluid volume in growth and maturation of the fetal sheep lung. J Clin Invest 86:1270-1277

6. Alcorn D, Adamson TM, Lambert TF, Maloney JE, Ritchie BC, Robinson PM 1977 Morphological effects of chronic tracheal ligation and drainage in the fetal lamb lung. J Anat 123:649-660

7. Nardo L, Hooper SB, Harding R 1998 Stimulation of lung growth by tracheal obstruction in fetal sheep: relation to luminal pressure and lung liquid volume. Pediatr Res 43:184-190

8. Flecknoe SJ, Wallace MJ, Harding R, Hooper SB 2002 Determination of alveolar epithelial cell phenotypes in fetal sheep: evidence for the involvement of basal lung expansion. J Physiol 542:245-253 
9. Flecknoe S, Harding R, Maritz G, Hooper SB 2000 Increased lung expansion alters the proportions of type I and type II alveolar epithelial cells in fetal sheep. Am J Physiol Lung Cell Mol Physiol 278:L1180-L1185

10. Danto SI, Shannon JM, Borok Z, Zabski SM, Crandall ED 1995 Reversible transdifferentiation of alveolar epithelial cells. Am J Respir Cell Mol Biol 12:497502

11. Shannon JM, Jennings SD, Nielsen LD 1992 Modulation of alveolar type II cell differentiated function in vitro. Am J Physiol 262:L427-L436

12. Flecknoe SJ, Wallace MJ, Cock ML, Harding R, Hooper SB 2003 Changes in alveolar epithelial cell proportions during fetal and postnatal development in sheep. Am J Physiol Lung Cell Mol Physiol 285:L664-L670

13. Cock M, Hanna M, Sozo F, Wallace M, Yawno T, Suzuki K, Maritz G, Hooper S, Harding R 2005 Pulmonary function and structure following mild preterm birth in lambs. Pediatr Pulmonol 40:336-348

14. Lines AL, Davey MG, Harding R, Hooper SB 2001 Effect of increased lung expansion on surfactant protein mRNA levels in lambs. Pediatr Res 50:720-725

15. Liu H, Hooper SB, Armugam A, Dawson N, Ferraro T, Jeyaseelan K, Thiel A, Koukoulas I, Wintour EM 2003 Aquaporin gene expression and regulation in the ovine fetal lung. J Physiol 551:503-514

16. Bolender RP, Hyde DM, Dehoff RT 1993 Lung morphometry: a new generation of tools and experiments for organ, tissue, cell, and molecular biology. Am J Physiol 265:L521-L548

17. Cole TJ, Solomon NM, Van Driel R, Monk JA, Bird D, Richardson SJ, Dilley RJ, Hooper SB 2004 Altered epithelial cell proportions in the fetal lung of glucocorticoid receptor null mice. Am J Respir Cell Mol Biol 30:613-619

18. Lines A, Nardo L, Phillips ID, Possmayer F, Hooper SB 1999 Alterations in lung expansion affect surfactant protein A, B and C mRNA levels in fetal sheep. Am J Physiol 276:L239-L245

19. Piedboeuf B, Laberge JM, Ghitulescu G, Gamache M, Petrov P, Belanger S, Chen MF, Hashim E, Possmayer F 1997 Deleterious effect of tracheal obstruction on type II pneumocytes in fetal sheep. Pediatr Res 41:473-479

20. Alcorn DG, Adamson TM, Maloney JE, Robinson PM 1981 A morphologic and morphometric analysis of fetal lung development in the sheep. Anat Rec 201:655667

21. Pinkerton KE, Green F 2004 Normal aging of the lung. In: Harding R, Pinkerton KE, Plopper CG (eds) The Lung: Development, Aging and the Environment. Academic Press, San Diego, pp 213-233
22. Tan RC, Ikegami M, Jobe AH, Yao LY, Possmayer F, Ballard PL 1999 Developmental and glucocorticoid regulation of surfactant protein mRNAs in preterm lambs. Am J Physiol 277:L1142-L1148

23. Schellhase DE, Emrie PA, Fisher JH, Shannon JM 1989 Ontogeny of surfactant apoproteins in the rat. Pediatr Res 26:167-174

24. Shimizu H, Miyamura K, Kuroki Y 1991 Appearance of surfactant proteins, SP-A and SP-B, in developing rat lung and the effects of in vivo dexamethasone treatment. Biochim Biophys Acta 1081:53-60

25. Sugahara K, Iyama KI, Kimura T, Sano K, Darlington GJ, Akiba T, Takiguchi M 2001 Mice lacking CCAAt/enhancer-binding protein-alpha show hyperproliferation of alveolar type II cells and increased surfactant protein mRNAs. Cell Tissue Res 306:57-63

26. Whitsett JA, Glasser SW 1998 Regulation of surfactant protein gene transcription Biochim Biophys Acta 1408:303-311

27. Weaver TE, Conkright JJ 2001 Function of surfactant proteins B and C. Annu Rev Physiol 63:555-578

28. Crouch E, Wright JF 2001 Surfactant proteins A and D and pulmonary host defense. Annu Rev Physiol 63:521-554

29. Bassett JM, Thorburn GD 1969 Foetal plasma corticosteroids and the initiation of parturition in sheep. $J$ Endocrinol 44:285-286

30. Magyar DM, Fridshal D, Elsner CW, Glatz T, Eliot J, Klein AH, Lowe KC, Buster JE, Nathanielsz PW 1980 Time-trend analysis of plasma cortisol concentrations in the fetal sheep in relation to parturition. Endocrinology 107:155-159

31. Durham PL, Wohlford-Lenane CL, Snyder JM 1993 Glucocorticoid regulation of surfactant-associated proteins in rabbit fetal lung in vivo. Anat Rec 237:365-377

32. Ballard PL, Ning Y, Polk D, Ikegami M, Jobe AH 1997 Glucocorticoid regulation of surfactant components in immature lambs. Am J Physiol 273:L1048-L1057

33. Cole TJ, Blendy JA, Monaghan AP, Krieglstein K, Schmid W, Aguzzi A, Fantuzzi G, Hummler E, Unsicker K, Schutz G 1995 Targeted disruption of the glucocorticoid receptor gene blocks adrenergic chromaffin cell development and severely retards lung maturation. Genes Dev 9:1608-1621

34. Ballard PL, Merrill JD, Godinez RI, Godinez MH, Truog WE, Ballard RA 2003 Surfactant protein profile of pulmonary surfactant in premature infants. Am J Respir Crit Care Med 168:1123-1128

35. Minoo P, Segura L, Coalson JJ, King RJ, DeLemos RA 1991 Alterations in surfactant protein gene expression associated with premature birth and exposure to hyperoxia. Am J Physiol 261:L386-L392 